\title{
Development, factor structure and application of the Dog Obesity Risk and Appetite (DORA) questionnaire
}

Eleanor Raffan, Stephen P Smith, Stephen O'Rahilly, Jane Wardle

Background: Dogs are compelling models in which to study obesity since the condition shares many characteristics between humans and dogs. Differences in eating behaviour are recognised to contribute to obesity susceptibility in other species but this has not been systematically studied in dogs. Aim: To develop and validate an owner-reported measure of canine eating behaviour and owner or dog related factors which can alter the development of obesity. Further, to then test variation in food-motivation in dogs and its association with obesity and owner management. Methods: Owner interviews, a literature review and existing human appetite scales were used to identify relevant topics and generate items for the questionnaire. Following a pilot phase, a 75 item online questionnaire was distributed via social media. Responses from 302 dog/owner dyads were analysed and factor structure and descriptive statistics calculated. Results were compared with descriptions of dog behaviour and management from a subset of respondents during semi-structured interviews. The optimum questions were disseminated as a 34 item final questionnaire completed by 213 owners, with a subset of respondents repeating the questionnaire 3 weeks later to assess test-retest reliability. Results: Analysis of responses to the final questionnaire relating to 213 dog/owner dyads showed a coherent factor structure and good test-retest reliability. There were three dog factors (food responsiveness and satiety, lack of selectivity, Interest in food), four owner factors (owner motivation to control dog weight, owner intervention to control dog weight, restriction of human food, exercise taken) and two dog health factors (signs of gastrointestinal disease, current poor health). Eating behaviour differed between individuals and between breed groups. High scores on dog factors (high food-motivation) and low scores on owner factors (less rigorous control of diet/exercise) were associated with obesity. Owners of more highly food-motivated dogs exerted more control over their dogs' food intake than those of less food-motivated dogs. Conclusions: The DORA questionnaire is a reliable and informative owner-reported measure of canine eating behaviour and health and management factors which can be associated with obesity development. The tool will be applicable to study of the canine obesity model and to clinical veterinarians. Results revealed eating behaviour to be similarly associated with obesity as exercise and owners giving titbits. 
1 Development, factor structure and application of the Dog Obesity Risk and 2 Appetite (DORA) Questionnaire.

3

4 Eleanor Raffan ${ }^{1 *}$, Stephen P. Smith ${ }^{2}$, Stephen O'Rahilly ${ }^{1}$, Jane Wardle ${ }^{3}$.

$5{ }^{1}$ Wellcome Trust-MRC Institute of Metabolic Science, Addenbrooke's Hospital, Cambridge, 6 CB2 OQQ, UK

7

8 2Department of Clinical Medicine, Addenbrooke's Hospital, Cambridge, CB2 0QQ, UK.

${ }^{3}$ Health Behaviour Research Centre, Department of Epidemiology and Public Health, University College London, London, WC1E 6BT, UK.

12

13

*Corresponding Author: Dr Eleanor Raffan, Wellcome Trust-MRC Institute of Metabolic

14 Science, Addenbrooke's Hospital, Cambridge, CB2 OQQ, UK. Telephone: +44 1223336792 15

16

Email: er311@cam.ac.uk

17 
ABSTRACT

19 Background: Dogs are compelling models in which to study obesity since the condition shares many characteristics between humans and dogs. Differences in eating behaviour are recognised to contribute to obesity susceptibility in other species but this has not been systematically studied in dogs.

Aim: To develop and validate an owner-reported measure of canine eating behaviour and owner or dog related factors which can alter the development of obesity. Further, to then test variation in food-motivation in dogs and its association with obesity and owner management.

Methods: Owner interviews, a literature review and existing human appetite scales were used to identify relevant topics and generate items for the questionnaire. Following a pilot phase, a 75 item online questionnaire was distributed via social media. Responses from $302 \mathrm{dog} / \mathrm{owner}$ dyads were analysed and factor structure and descriptive statistics calculated. Results were compared with descriptions of dog behaviour and management from a subset of respondents during semi-structured interviews. The optimum questions were disseminated as a 34 item final questionnaire completed by 213 owners, with a subset of respondents repeating the questionnaire 3 weeks later to assess test-retest reliability.

Results: Analysis of responses to the final questionnaire relating to $213 \mathrm{dog} /$ owner dyads showed a coherent factor structure and good test-retest reliability. There were three dog factors (food responsiveness and satiety, lack of selectivity, Interest in food), four owner factors (owner motivation to control dog weight, owner intervention to control dog weight, restriction of human food, exercise taken) and two dog health factors (signs of gastrointestinal disease, current poor health). Eating behaviour differed between individuals and between breed groups. High scores on dog factors (high food-motivation) and low scores on owner factors (less rigorous control of diet/exercise) were associated with obesity. Owners of more highly food-motivated dogs exerted more control over their dogs' food intake than those of less food-motivated dogs.

43 Conclusions: The DORA questionnaire is a reliable and informative owner-reported measure of canine eating behaviour and health and management factors which can be associated with obesity development. The tool will be applicable to study of the canine obesity model and to clinical veterinarians. Results revealed eating behaviour to be similarly associated with obesity 47 as exercise and owners giving titbits. 
49 Obesity is a common problem in dogs and is associated with a plethora of diseases and physiological changes that are reminiscent of those seen in humans (Edney \& Smith 1986; German 2006; Zoran 2010). Dogs share an environment with their human owners and are exposed to similar obesogenic factors such as a sedentary lifestyle and ready availability of calorie-dense, highly palatable food (Raffan 2013). Consequently, canine obesity is worthy of study not only to address veterinary questions but also because dogs are compelling model organisms for research of translational relevance (Raffan 2013).

Obesity is ultimately the consequence of energy intake exceeding expenditure. However, there is an increasing recognition that energy homeostasis is a closely regulated neurobiological process under the influence of genetic variants which often modify an individual's behavioural phenotype related to feeding style, energy intake and food seeking behaviour (Carnell \& Wardle 2009; Farooqi 2011; Raffan 2013; Yeo \& Heisler 2012). People demonstrate marked variability in appetite and food preferences. Many studies have shown that variation in eating styles is associated with obesity. Genetic, endocrine and psychological mechanisms for this association have been explored (French et al. 2012).

There is evidence from experimental feeding trials that variability in eating behaviour exists between individual dogs and breeds (Hewson-Hughes et al. 2013) and a single veterinary study reported appetite (tested with a single question) to contribute to dog obesity (Sallander et al. 2010). However, individual feeding experiments are expensive and time consuming, as are similar protocols applied to human research subjects (Gibbons et al. 2014).

Consequently, questionnaire based tools to assess eating traits such as food responsiveness and satiety responsiveness in people are well established (Llewellyn et al. 2011; van Strien et al. 2006; Wardle et al. 2001). No such tool has been reported for dogs and we identified the need for one to assess differences in eating behaviours between individual dogs. The role of dog owners as caregivers with a close emotional bond to their wards is reminiscent of that of parents with children so we considered questionnaires about eating behaviour for children to be a good model for developing such a tool.

Questionnaires for children and babies drew upon established theories and research (Llewellyn et al. 2011; Wardle et al. 2001). No such systematic research examining dog eating styles exists on which this questionnaire might be based. However, we can infer that variation exists because animal care texts refer indirectly to eating styles by advising on how to manage dogs with food related behaviours which are considered desirable or not. Additionally, food is commonly used as positive reinforcement during training (Hand et al. 2010; Lindell 2009).

82 Since dog owners are generally responsible for providing food and enabling exercise for their 83 pets, it is sensible that a questionnaire considering the influence of food-motivation on obesity 84 should also collect information about owner or dog factors which might moderate the 
85 development of obesity. Obesity in dogs has previously been associated with gender, neuter 86 status, age, breed, feeding practices (e.g. provision of human food, titbits, weighing/measuring

87 food), owner income, obesity and age, the nature of the owner-dog relationship and exercise 88 (Bland et al. 2009; Colliard et al. 2006; Courcier et al. 2010; Edney \& Smith 1986; Kienzle et al. 89 1998; Nijland et al. 2010; O'Neill et al. 2014; Robertson 2003; Rohlf et al. 2010; Sallander et al. 90 2010; Warren et al. 2011).

91 Only one previous study (Sallander et al. 2010) considered appetite or food motivation, and then only with a single question. However, anecdotally, veterinary surgeons and pet owners commonly report some individual dogs or breeds/types of dog to be particularly food motivated or 'fussy' eaters.

The primary aim of this work was to develop an owner-reported questionnaire to assess dog eating behaviour as well as dog health and owner management factors which can affect the development of obesity and validate it using different measures (test test-retest reliability, internal consistency, face validity, construct validity and criterion validity).

A secondary aim was to use the questionnaire to test whether variability in dog food-motivation existed and, if so, how it was associated with different owner management styles, and obesity. The null hypotheses were that there would be no difference in eating behaviour between dogs or between lean and overweight dogs, and that owners would not manage food differently in dogs with different eating behaviours.

\section{MATERIALS AND METHODS}

The study was approved by the Ethics and Welfare Committee of the Department of Veterinary Medicine, University of Cambridge (CR125).

\section{Questionnaire Development}

108 Defining variability in food related behaviour and owner management

109 Items to be included in the questionnaire were designed using information from three sources:

110 1) A minority of items were drawn directly from two existing questionnaires for assessing eating 111 behaviour in children and babies (Llewellyn et al. 2011; Wardle et al. 2001). Existing items 112 were selected if they could be deemed relevant to dogs. For instance, some items could be 113 adapted by substituting 'dog' for 'child', such as 'my child finishes his/her meal very quickly'.

114 Others were rejected as they asked about interactions not recognised or defined in dogs, such as 115 'I use puddings as a bribe to get my child to eat his/her main course'. Furthermore, these 116 resources were used to identify a list of topics which might be relevant to dogs or owner 117 management. Amongst those topics was 'emotional eating' which we defined as eating more or 118 less food during negative emotional states, following Wardle et al (Wardle et al. 2001).

119 2) Veterinary texts and clinical experience were used to identify further areas where feeding 120 behaviours were variable between dogs, and where owners were likely to make decisions about 
121 how they interact with their dogs with regard to food. Dog owners have commonly expressed

122 concern to one author (ER, a veterinary surgeon) about behaviours they considered undesirable

123 such as very fast eating, fussiness or choosiness, 'begging' for food, and snatching food, or

124 discussed other behaviours as desirable such as waiting patiently to be fed, eating only on

125 command, and taking proffered titbits gently. Other behaviours such as food-related aggression,

126 stealing human or other pets' food, coprophagia, or eating non-food items such as stones or

127 socks are also more formally addressed (Lindell 2009). Additionally, food is advised as a

128 training aid (Lindell 2009). Literature reviews were also used to identify known factors which

129 predispose dogs to obesity (see Introduction).

130 3) Findings from (1) and (2) were used to generate a framework for semi-structured interviews.

131 Interviews with an opportunistic sample of dog owners who had volunteered their dogs for

132 participation in a different genetic research project were performed by a single author (ER) who

133 is an experienced veterinary clinician. Detailed, hand-written contemporaneous notes were made

134 during and immediately after each interview.

135 Initially, owners were encouraged using open questions to talk about the eating behaviour and

136 feeding, exercise and other management of a single dog they owned. Comparisons between

137 other dogs they knew or owned were encouraged, to draw out differences in eating behaviour.

138 Interviews were conducted non-judgementally and presented as being about natural variation in

139 dog behaviour, to encourage owners to be as candid as possible about their management

140 practices. The interviewer avoided pejorative terms such as 'greedy' and 'begging'. Areas

141 addressed specifically in the semi-structured interviews were broadly divided into 'dog' and

142 'owner management' topics which are summarised below. A copy of the primer used for the

143 interviews is included as Supplementary file 1.

144 Dog topics were: (a) responsiveness to food (behaviour at mealtimes or when food offered in

145 between meals, tendency to inspect food before eating), (b) speed of eating (of meals or offered

146 titbits), (c) satiety responsiveness (interest in food in between meals, apparent desire for more

147 food than usually offered), (d) general interest in eating (food seeking behaviour on walks,

148 behaviour when human food was being prepared or eaten), (e) food fussiness (selectivity about

149 particular foods, refusal to eat some types of dog food, choosiness about which titbits to eat), (f)

150 emotional eating (change in appetite in response to owner-perceived changes in a dog's stress

151 levels), (g) scavenging/stealing food (eating items owners consider revolting such as faeces,

152 indigestible such as stones, or illicit such as human food left within reach but in places they are

153 taught not to access), and (h) food related aggression (to humans or other dogs).

154 Owner management topics were: (a) control over eating (regulation of food intake by offering

155 measured amounts at mealtimes, regulating titbits, and stopping scavenging or stealing), (b)

156 prompting/encouragement (offering multiple diets or addition of flavoursome foods, or

157 encouragement given to dogs to eat), (c) instrumental feeding (use of food rewards in training),

158 (d) emotional feeding (whether they fed their dogs to provide reassurance), (e) importance of 
159 body shape (how important owners felt it was to manage their dogs' weight, and how hard they

160 perceived they worked to do so), (f) exercise (importance attributed by owners to exercise,

161 nature, duration and frequency of exercise in a typical week), and (g) level of training (whether

162 dogs were trained for a specific purpose, level of discipline, ability to stop undesirable

163 behaviours successfully, desire to control begging/scavenging or other undesirable behaviour).

164 Owners were asked specifically about their dogs' health (including questions about dietary

165 sensitivities, or continuous or intermittent clinical signs of gastrointestinal upset) in order to

166 identify any actual or suspected disease which could affect appetite or eating behaviour.

167 Generation of Items for Questionnaire

168 Systematic analysis of interview data was performed by manual coding of copies of the

169 contemporaneous notes from each interview by a single investigator who also performed the

170 interviews (ER) (Gibbs 2007). Coding of the information was categorical and both concept

171 driven (some codes generated from literature review as above) and data driven (additional codes

172 which emerged from interview data) (Gibbs 2007). Following coding, the frequency with which

173 each category was coded in the interview data was used to prioritise how many associated items

174 should be included in the pilot questionnaire.

175 The repeated review of the data was also used to extract recurring phrases and descriptors used

176 by owners to describe their dogs or management practices. Final items were constructed using

177 that information, coding data and adaptation from existing human questionnaires.

178 Questionnaire Refinement and Sampling

179 Below, the different versions of the questionnaire used during the process of development are

180 outlined, along with a brief summary of what was tested at each stage. Later sections address the

181 sampling methods and statistical methods applied at each stage. A flow diagram to summarise

182 this process is shown in Figure 1.

183

184

185

186

187

188

189

190

191

192

193

194

195

\section{Pilot Survey - Identifying Initial Problems and Testing Face Validity}

Seventy-seven items were included in a preliminary questionnaire with a single response format ('never', 'rarely', 'sometimes', 'often', and 'always'). Items related to dog eating behaviour and owner management were mixed in random order. ER discussed each item with a panel of experts including co-authors (JW and SS) and 4 veterinary colleagues with an interest in behaviour. Dog owners (sample 1) were invited to test the pilot questionnaire either online or on paper. Those who completed a paper copy and were encouraged to discuss the questions (particularly any areas where they were unclear what was being asked or weren't sure how to answer for their dog) with an investigator as they did so and those who completed it online were invited to make a text comment after each item and talked to an investigator afterwards. Contemporaneous notes were made on all discussions. Responses were critically evaluated to test face validity (i.e. did different respondents interpret items in the same way as each other and/or in the way intended when they were composed?). 
Factor Structure and Questionnaire Refinement

197 A refined 75 item questionnaire was published and disseminated online (sample 2). In addition

198 to the items composed above, the name, age, breed and gender of each dog was recorded.

199 Owners were invited to assign their dog a body condition score (a numerical, categorical scale of

200 dog body morphometry which has been shown to be a reliable indicator of body adiposity and

201 takes into account the variability of body shape in different breeds) on a scale of $0-5$ where 0 is

202 excessively thin, 3 optimal and 5 obese, guided by a chart with representative images and

203 accompanying descriptors (Laflamme 1997; McGreevy et al. 2005). Questions about breed,

204 gender and body condition score were not compulsory. Respondents also had the option of

205 providing their name and contact details on the understanding that some would be contacted to

206 be interviewed about the subject of the survey.

207 Factor analysis was performed and responses to individual questions statistically described (see

208 statistics section). Of respondents who had provided contact details, a subset were contacted by

209 telephone and interviewed using the same semi-structured format as previously, but with

210 additional questions about particular answers which appeared discordant with other questionnaire

211 responses.

212 The number of questions was reduced to minimise the length and avoid clearly repetitive items.

213 Questions which had a broad range of answers and loaded onto just one factor were prioritised

214 (see statistics section).

215 Testing the refined questionnaire

216 The resulting shorter questionnaire was distributed online (sample 3). Three weeks after they

217 had taken the questionnaire, respondents were invited to repeat it. Factor analysis and analysis

218 of test-retest reliability were performed (see statistics section).

219 Method of Dissemination

220 At each stage, the online version of the questionnaire was composed, formatted and published 221 using commercially available software (Qualtrics, Provo, USA). The survey software prevented

222 more than one submission per internet provider (IP) address, and respondents with more than one

223 dog were asked to answer about only one dog. For online dissemination, posts were made on

224 Facebook and Twitter, and interested parties including leaders of rescue organisations, the

225 Kennel Club, dog-related businesses and friends and colleagues of the authors were encouraged

226 to disseminate the invitation to participate more widely.

\section{Sampling}

228 Sample 1 (pilot questionnaire) was a small convenience sample of dog owners who were 229 colleagues or associates of ER.

230 For sample 2 and 3, the questionnaire was disseminated exclusively online and thus they can be

231 considered convenience samples drawn from a large pool of dog owners active on social media. 
232 A subset of sample 2 were contacted by telephone to discuss their answers to the survey. Those 233 individuals were initially self-selecting (because they opted to give their contact details). From

234 those owners, owners were chosen to be representative of a range of differently scoring dogs of

235 different breeds and ages, from different parts of the country.

236 All owners in sample 3 who had given their contact details were invited to retake the

237 questionnaire 3 weeks later and all responses received were analysed. Responses were not

238 permitted from respondents who had taken previous versions of the questionnaire.

239 Questionnaire Scoring System

240 Since both 4 and 5 option scales were used, items were scored as a percentage of the maximum

241 to avoid 5 option scaled questions having a greater impact than 4 option scaled questions.

242 Therefore, 'never' was assigned 0, 'rarely' 25, 'sometimes' 50, 'often' 75, and 'always' 100.

243 Similarly, 'not at all true' was assigned 0 , 'somewhat true' 33.3 , 'mainly true' 66.6 , and

244 'definitely true' 100 . Where items within a factor invited opposite answers for the same dog,

245 scores for the minority items were reversed. (For instance, within a theoretical factor about dog

246 size, 'true' for 'my dog is very small' would score 100 as would 'false' for 'my dog is very big'.)

247 The working scores for the questionnaire were the individual factor scores, a combined 'dog

248 food-motivation score', and a combined 'owner management score'.

249 Individual factor scores were calculated as percentages:

$250=$ (sum of item scores for that factor) / (sum of maximum possible item scores for that factor) $\mathrm{x}$ $251 \quad 100$

252 The dog food-motivation score was calculated from all the dog items:

$253=$ (sum of item scores for all dog items) / (sum of maximum possible dog item scores) $\mathrm{x} 100$

254 The owner management score was calculated from all items in factors 1-3 of management and

255 health factors (i.e those related to food control and perception of dogs' weight):

$256=$ (sum of item scores for all items in factors 1-3) / (sum of maximum possible item scores in

257 factors $1-3) \times 100$

258 Statistical Analysis

259 All numerical analyses were conducted using the $\mathrm{R}$ statistical programming language (R Core

260 Team 2013).

261 Summary of Validation Tests

262 Different validation methods as applied to veterinary questionnaires have recently been reviewed

263 and definitions were applied as in that paper (Belshaw et al. 2015).

264 Test-retest reliability was measured on the final version of the questionnaire. 
265 Face validity (a type of content validity) was assessed during the pilot survey stage by

266 interrogating an expert panel and dog owners on their interpretation of items forming part of the 267 questionnaire.

268 Results of factor analysis, the Tucker Lewis index (a measure of factoring reliability) and

269 Cronbach's alpha are reported as measures of internal consistency.

270 Construct validity was assessed by testing for hypothesised relationships between different

271 factors: we hypothesised that the three dog factors would be positively correlated with one

272 another and with the overall dog food-motivation score; also that owner factors related to food

273 control would be correlated with one another and with the overall owner management score.

274 Criterion validity for known groups was assessed by testing whether dog food-motivation scores

275 were different between different dog breeds, and dogs with different body condition scores.

276 Furthermore, we hypothesised that factors which encompassed previously reported risk factors

277 for obesity would be positively associated with body condition score.

278 Exploratory Factor Analysis (Samples 2 and 3)

279 Parallel and factor analysis algorithms were used, as implemented in the Psych R package

280 (Revelle 2015). Results from parallel analysis informed the number of factors analysed

281 subsequently in exploratory factor analysis. Factor loadings of greater magnitude than 0.4 were

282 considered substantial. Plotting functions were implemented in the ggplot2 package (Wickham

283 2009). The Tucker-Lewis index of factoring reliability and Cronbach's alpha were calculated

284 using the functions in the Psych R package. For the Tucker-Lewis index, 0.9 was considered to

285 indicate good factoring reliability. For Cronbach's alpha, results $>0.6$ were considered

286 acceptable, $>0.7$ good and $>0.8$ very good.

287 Reducing Items - Refining the Questionnaire

288 After factor analysis of Sample 2, questions which had a broad distribution of answers (low

289 skew), loaded onto just one factor (low complexity), and much of whose variability could be

290 explained by the factors identified (high communality) were prioritised. All three were

291 calculated in the Psych R package as part of exploratory factor analysis (see above).

292 Skew is a measure of the asymmetry of the probability distribution of a real-valued random

293 variable about its mean. Low skew was considered desirable and items with skew $>1.25$ or $<-$

2941.25 were considered poor. Complexity refers to the number of factors upon which a variable

295 has moderate or high loadings. Complexity $<2$ was considered desirable and items with

296 complexity $>3$ were considered poor. Communality refers to the proportion of variance in each

297 variable which can be explained by the factors. Communality greater than 0.5 was considered

298 desirable and items with communality $<0.35$ were considered poor. 
300 Final validation and testing the hypotheses defined as secondary aims were performed on the

301 data from Sample 3. i.e. The results from the final version of the questionnaire. Descriptive

302 statistics were generated for all factors. Data for all factors and other variables were tested for

303 normality of distribution by measuring skew and kurtosis, and by graphical analysis using

304 frequency distribution and quantile-quantile plots. Methods for specific tests applied at this stage

305 are detailed below.

306 Test-retest Reliability

307 Test-retest reliability was analysed using the cor.test function in R, which calculates test statistics

308 to measure the significance of correlation between scores for each factor at the different time

309 points. For correlation coefficients, $\mathrm{R},>0.5$ was considered good and $>0.75$ very good. For

310 interpretation of $\mathrm{P}$ values, see below.

\section{Correlation}

312 When associations between quantitative variables (e.g. factor scores, body condition scores, age)

313 are reported, correlation was tested using Pearson correlation for normally distributed data and

314 Spearman correlation for data which were not normally distributed. Correlation coefficient, R,

$315>0.5$ was considered good and $>0.75$ very good.

316 Tests to Compare Groups

317 Intergroup comparisons were assessed using ANOVA (e.g for breeds) or paired t-tests (e.g. for 318 gender).

\section{Generation of a Minimum Model to Explain Body Condition Score}

320 Stepwise multiple regression to a minimum model was performed in R using factor scores as 321 predictors of body condition score with a final model defined when all remaining factors were 322 significant independent predictors.

\section{Significance Levels}

324 For comparisons involving age, gender and breed, testing the hypotheses defined in the 325 introduction, assessing test-retest reliability and defining the minimum model during stepwise 326 multiple regression, significance was determined by the test statistic $p<0.05$. Since testing for 327 correlations between dog and management/health factors involved multiple testing, a Bonferroni 328 corrected level of significance of $p<0.001$ was used for all those comparisons. 


\section{Questionnaire Development}

332 Defining variability in food related behaviour and owner management

333 During preliminary interviews owners were keen to talk about their dogs and commonly

334 volunteered information about many or all of the topics in the interview framework. Many

335 owners described dog eating behaviours in pejorative and frank ways. For example, dogs were

336 commonly described as 'greedy'. In contrast, they tended to avoid pejorative terms for

337 behaviours which textbooks commonly describe as suitable for modification by training. For

338 example, owners would commonly describe behaviours such as hanging around at human

339 mealtimes, or using eye gaze direction to identify food. Owners interpreted those behaviours as

340 soliciting food but would deny that their dog 'begged' for food if asked directly. These findings

341 were taken into account when designing items for the questionnaire.

342 Generation of Items for Questionnaire

343 Most of the topics related to eating behaviour and owner management emerged during owner

344 interviews and recurrent phrases were used to write items for the questionnaire. Of 34 codes

345 applied to the data, some recurred frequently, such as differences in selectivity (for example, 'my

346 dog will eat anything' or 'my dog is interested in human food but only actually eats the things he

347 likes'). Other codes were not commonly applicable and hence not represented in the

348 questionnaire. For instance, only 1 out of 50 dog owners reported a difference in their dog's

349 eating behaviour during periods of stress (interpreted as 'emotional eating') and none reported

350 feeding their dogs to provide comfort when upset, although use of food as a reward for good

351 behaviour after a stress such as a veterinary visit was common, which might be viewed similarly.

352 Following analysis, 77 items were written for inclusion in the pilot questionnaire.

353 Sampling

354 For sample 1 (pilot survey), completed questionnaires were received from 22 dog/owner dyads

355 representing 10 breeds. Fifteen completed a paper copy and 7 completed the questionnaire

356 online. Mean (SD) age was 6 years (3.8).

357 For Sample 2, the questionnaire was started by 298 owners but 78 (26\%) failed to finish within 2

358 weeks meaning completed questionnaires were analysed from $224 \mathrm{dog} /$ owner dyads. Dogs had

359 mean (SD) age of 6 years (3.5). Labradors predominated in this sample $(n=159,86 \%)$.

360 Seventeen crossbreed dogs and 7 or fewer dogs from 23 other breeds completed the group.

361 Email addresses were provided for 204/224 owners in Sample 2 who completed the survey and a

362 subset of 20 were contacted by telephone for follow-up interview.

363 For Sample 3, the questionnaire was started by 244 owners but $39(16 \%)$ failed to finish within 2

364 weeks meaning completed questionnaires were analysed from $205 \mathrm{dog} / \mathrm{owner}$ dyads. The median

365 time to complete the entire questionnaire was 9 minutes (mean 15 minutes). The mean (SD) dog 
366

367

368

369

370

371

372

373

374

375

376

377

378

379

380

381

382

383

384

385

386

387

388

389

390

391

392

393

394

395

396

397

398

399

400

401

age was 6 years $(3.8)$ and median age $(25$ th and 75 th centiles) 6 years $(3,9)$. Thirty-seven breeds were represented, including 40 cross-breeds, 101 Labrador retrievers, and 6 or fewer dogs from each of 34 other breeds. There were 106 male dogs ( 4 entire, 10 neutered, 92 not reported), 79 female dogs ( 2 entire, 17 neutered, 60 not reported) and 20 with gender not reported.

Email addresses were provided for 185/205 owners in sample 3 who completed the survey and all were invited to take the survey again 3 weeks later. Sixty-seven complete responses were received within 7 days and were analysed for test-retest reliability.

For both Samples 2 and 3, Labrador retrievers were the predominant breed. This was found to be related to prominent posts on social media by the head of a Labrador retriever rescue organisation. Labrador retrievers are estimated to make up 10-16\% of the UK dog population (Asher et al. 2011) meaning the breed was significantly (Chi squared test, $\mathrm{p}<0.001$ ) overrepresented in both samples.

\section{Pilot Survey - Identifying Initial Problems}

After the pilot stage (Sample 1) assessment of face validity, two items were discarded, and wording was modified to increase clarity for others. The response format was changed for 48 of the remaining items to 'not at all true', 'somewhat true', 'mainly true', and 'definitely true' because testers felt that format better suited particular items.

\section{Factor Structure}

Data from Sample 2 were tested using exploratory factor analysis. Of the 75 items, all but 6 were associated with one or more of 9 factors. Three factors were related to dog eating behaviour, 4 to owner management and two to dog health. Although the factors were reminiscent of the $8 \mathrm{dog}, 7$ owner and 1 health topics identified in the methods and examined during interviews, there were fewer factors and there was significant overlap; that is, topics which were a priori considered separately did not always separate into different factors using this unsupervised statistical approach.

\section{Reducing Items - Refining the Questionnaire}

There were 23 items with skew $>1.25$ or $<-1.25$. Of these, 5 were retained due to their importance in other regards and the remaining 18 discarded. Low communality was identified for 20 items; of these 2 were retained and 18 discarded. High complexity was identified for 21 items; of these 4 were retained and 17 discarded. All 6 items which were retained despite falling outside the above categories are shown in Table 4. Overall, 41 questions were eliminated (several failed for more than one reason), leaving 34 in the final questionnaire.

Questions with high skew were typically included in the pilot survey for completeness despite not having emerged from owner interviews (e.g. 'I think my dog could do with gaining some weight') or had emerged during owner interviews but were rarely positively answered across a larger population (e.g. 'My dog grazes at the food in his/her bowl throughout the day). 
402 Questions with low communality were typically querying management factors which did not 403 directly impact on the factors identified (e.g. 'My dog's exercise varies throughout the week'

404 captured variability that exists in some dogs' lives but other items better captured the amount or 405 intensity of exercise they received).

406 Questions with high complexity typically used language that was hard to define or were about 407 behaviour that varied over time (e.g. 'My dog is lazy').

408 Validating the Final Questionnaire

409 Internal Consistency

410 For the final version of the questionnaire (Sample 3), the factor structure identified previously

411 was maintained (Tables 1 and 2). The Tucker-Lewis index of factoring reliability was 0.94 for

412 dog factors and 0.97 for owner management factors. The factor structures accounted for $58 \%$ of

413 variability for the dog factors, and $62 \%$ for the owner management and health factors.

414 Cronbach's alpha was good or very good for all factors (Table 3).

\section{Test-retest Reliability}

416 Test-retest reliability was good or very good for all factors (Table 3).

\section{Construct Validity}

418 For dog factors, correlation between individual factors and the overall dog food-motivation score 419 was high (Table 5a); as a consequence the composite 'dog food-motivation score' was used as a 420 single measure of eating behaviour. Correlation was low-moderate for management factors 421 when compared pair-wise but good when compared with a combined 'owner management score' 422 (Table 5b).

423 The finding of only low-moderate correlation between 'owner perception', 'owner intervention 424 to control weight' and 'restriction of human food' prompted us to review the semi-structured 425 interview notes and explained how although the overall scores were associated, there was less 426 clear association between individual factors. To explain this, we offer two example owners: 427 Owner 1 reported they had a fit dog of good weight (scoring low in 'owner perception') but 428 achieved that by very careful management (scoring high for 'owner intervention') but with a 429 feeding regime that included regular human titbits (scoring moderately for 'human food').

430 Overall, such owners would typically score highly on the owner management score. In contrast, 431 Owner 2 recognised their dog was overweight (scoring high in 'owner perception'), fed their dog 432 ad libitum (scoring low for 'owner intervention') and included regular human titbits (scoring 433 moderately for 'human food'). Overall, such owners would typically have a low owner 434 management score. However, on the 'human food' factor alone, they scored similarly to the first 435 example owner. 
437 Factors identified which represented previously considered risk factors for obesity in dogs were

438 'Exercise taken' and 'Restriction of human food'. The hypothesis that these would be associated

439 with body condition score was confirmed: there were significant correlations between high body

440 condition score and low scores for restriction of human food (Pearson $r=0.1867, p=0.0157$ )

441 and low exercise scores (Spearman $r=-0.29, p=0.0002$ ). There were also significantly

442 different dog food-motivation scores for dogs of different breed groups and body condition

443 scores (see below for further information).

\section{Questionnaire Findings}

445 Dog Characteristics

446 Findings are presented from Sample 3 for which the questionnaire was completed for 205

447 dog/owner dyads. Owners reported body condition scores for 165 dogs. Body condition scores

448 ranged from $1-5$ and were normally distributed with a strong peak at the optimum body shape

449 (Figure 2).

450 Variability in Canine Appetite

451 Dog food-motivation scores varied widely between individual dogs, ranging from $9-100 \%$ with 452 a bimodal distribution (Figure 3).

453 There was a weak ( $\mathrm{r}$ squared 0.146$)$ but statistically significant $(\mathrm{p}=0.037)$ correlation between 454 age and dog food-motivation score. There was no difference between dog food-motivation score 455 between male and female dogs. Neuter status was only available for a small subset of dogs, 456 limiting the utility of analysis of the effect of neuter status, but mean dog food-motivation scores 457 were higher in neutered dogs (mean \pm SEM of 6 entire dogs $58.67 \pm 9.687$ vs $77.11 \pm 3.211$ for 45827 neutered dogs, $\mathrm{p}=0.0304)$.

459 Given the small numbers for some breeds, British Kennel Club groupings were used for inter460 breed analysis. Within the gundog group, 101/118 were Labrador retrievers. There was a 461 significant difference between dog food-motivation scores between breed groups (Figure 4, 462 ANOVA $\mathrm{p}<0.0001)$.

463 Owner Management, Exercise and Health

464 Owner management scores were widely and approximately normally distributed (Figure 5a). 465 Exercise scores were reasonably widely distributed but were slightly skewed towards $100 \%$, 466 suggesting the majority of dogs were considered by their owners to be very active (Figure 5b).

467 The scores for current disease and signs of gastrointestinal disease were skewed strongly, 468 showing most dogs had no persistent health problems or signs of gastrointestinal disease (Figure 4695 , $\mathrm{c}$ and d). There was no difference in body condition score or food-motivation score between 470 dogs whose owners indicated they had any signs of gastrointestinal disease and those whose 471 owners indicated they had no signs of gastrointestinal disease. Similarly, there was no 
472 significant correlation between gastrointestinal disease score and dog food-motivation score 473 (correlation coefficient $\mathrm{R}=0.033, \mathrm{p}=0.64$ ). Dogs which scored 0 for current disease (indicating 474 no regular veterinary visits or veterinary advised restriction of exercise) had significantly lower 475 body condition scores than dogs which had any positive answers to those questions; there was no 476 difference in food-motivation between the two groups. Similarly, there was no significant 477 correlation between current disease score and dog food-motivation score (correlation coefficient $478 \mathrm{R}=0.037, \mathrm{p}=0.59$ ). A post hoc power calculation showed that a sample size of $200 \mathrm{had} 80 \%$ 479 power to detect a significant $(\alpha=0.05)$ correlation greater than 0.175 .

480 Obesity, Eating Behaviour, and Owner Management.

481 High dog food-motivation scores were significantly associated with higher body condition scores 482 (Figure 6). Dog food-motivation score was positively correlated with owner management score 483 (Figure 7a). Consistent with the effect of high food-motivation on body condition score, there 484 was also a positive correlation between body condition score and owner management score 485 (Figure 7b).

486 As stated above (under Criterion Validity), there were significant correlations between high body 487 condition score and low scores for restriction of human food and low exercise scores.

489 Stepwise multiple regression to minimum model showed the following significant predictors of 490 body condition score: food responsiveness \& satiety (positive, $p=0.02$ ), exercise (negative, $491 \mathrm{p}<0.01) \&$ restriction of human food (negative, $\mathrm{p}=0.03$ ). Effect magnitudes were similar for 492 each predictor $(0.018,0.019,0.016$ respectively) implying a similar contribution to the body 493 condition score for each factor.

\section{DISCUSSION}

495 The primary aim of this research was to design an owner-reported measure of dog food496 motivation, owner management and dog health factors which influence body weight. We report 497 the development, validation and application of the DORA questionnaire, and show it is a robust 498 and widely applicable tool suitable for use in research of the canine obesity model, or as a 499 veterinary clinical tool. Below, the factor structure, methods of development and validation, and 500 comparisons with similar human questionnaires will be discussed. Subsequently, data 501 addressing the secondary aim, to test how dog appetite and owner management are related, are 502 discussed.

503 Questionnaire Development

504 Factor Structure

505 Analysis showed a clear factor structure which divided into 3 measures of dog eating behaviour, 5064 of owner management and 2 related to health. Divisions were largely logical and self507 explanatory from the items contained within. 
508 Items regarding signs of gastrointestinal disease (3 items) formed a clear factor on analysis.

509 Additionally, the 'current disease' category included two items which neither clustered with each

510 other nor other factors. For this development work, further information was not collected about

511 the nature of medical problems but this would be easily achieved using online or paper

512 questionnaire formats if of relevance. Health questions were included because disease can

513 influence a dog's propensity to gain or lose weight either directly or secondary to drug therapy.

514 Additionally, we considered that a dog's display of food-related behaviour might be the net

515 result of their inherent neurological drive to eat and physical factors such as nausea which could

516 reduce food intake.

517 A particular concern was that subclinical or poorly recognised gastrointestinal disease (e.g. food

518 allergy or chronic pancreatitis) might stop dogs with high food-motivation from expressing that

519 behaviour. Presence of gastrointestinal signs did not affect body condition score or food-

520 motivation, suggesting that should not be a great concern in future studies. The fact that regular

521 vet visits or restricting exercise on vet advice was associated with higher body condition scores

522 but no difference in food-motivation might reflect the effect of restricted exercise, medications or

523 that obesity predisposes to disease (German 2006; Raffan 2013; Zoran 2010).

524 We considered whether the lack of association between Current Disease or Gastrointestinal

525 Disease factor scores and dog food-motivation scores might be due to the study being

526 underpowered (since a fairly small proportion of dogs scored highly for either factor). However,

527 a post hoc power calculation showed our study would have been powered to find a low

528 correlation $(\mathrm{R}>0.175)$ and the fact that neither factor was in actuality correlated significantly or

529 with $\mathrm{R}>0.04$ means we feel the conclusions drawn above are valid.

530 Questionnaire Validation

531 Several measures of the validity of the DORA questionnaire are reported and were found to be

532 good. Analysis of reliability was assessed using answers by the same respondents made 3 weeks

533 apart (test-retest reliability), a time frame which is on the cusp of being intra-rater reliability

534 (which is usually assessed over a slightly shorter time frame) (Belshaw et al. 2015). Inter-rater

535 validity was not measured in this study.

536 As a test of criterion validity, we hypothesised that dog factors would correlate with each other

537 and dog food-motivation score and that similar would be true for owner management factors.

538 The former was true. However, although each owner factor correlated with the overall owner

539 management score (suggesting broad agreement amongst those constructs), it was notable that

540 correlation between individual factors was less good. We concluded that it whilst it was valid to

541 explore the data using the overall owner management score as we have at times in this paper, any

542 future work designed to test how particular facets of owner management might affect dog obesity

543 would be better served by considering each owner and management factor separately. 
544 It is notable that, in the absence of a reference standard measure for dog food motivation, no measure of criterion (concurrent) validity could be applied to this questionnaire. Similarly, we chose not to collect in depth quantitative data about owner factors (e.g. number of walks per day, grams of food offered, nature of titbits). Responses to those types of questions have previously been shown to be unreliable and to fail to capture the complexity of different types of exercise or foods (German et al. 2011; Sallander et al. 2001; Slater et al. 1992). As a result, criterion (concurrent) validity could not be applied to management factors either. Instead, for both, we used semi-structured interviews with a subset of Sample 2 to check that what owners were answering in the questionnaire corresponded with more in depth verbal descriptors of each factor. The internal consistency of the items in these factors suggests that the approach adopted of capturing qualitative data has been successful.

Further validating this qualitative approach, the results confirmed some previously reported features of canine obesity that act as an external validation for the questionnaire: compared to lean dogs, obese dogs were more likely to be fed human food and titbits, have owners who were less likely to weigh/measure their food allowance, and exercise less (Bland et al. 2009; Courcier et al. 2010; Kienzle et al. 1998; Robertson 2003; Sallander et al. 2010; Warren et al. 2011). All those points have been discussed when first reported, and are intuitive. It is remarkable, however, that we have demonstrated those associations using just 16 relevant items, rather than using in depth, quantitative questions about each aspect.

\section{Comparison with human eating behaviours}

In comparison with similar human questionnaires, there was moderate similarity but fewer factors were identified (Llewellyn et al. 2011; Wardle et al. 2001). Several dog factors are directly analogous to those identified in studies of babies and children (e.g. 'food responsiveness and satiety' is analogous to the 'food responsiveness'). However, dog owners only rarely recognised emotional under-eating or over-eating in their dogs, reported they did not feel fit to judge their dogs' enjoyment of food, and confirmed that dogs universally had free access to water at all times, meaning other factors identified in children and babies are not relevant.

There was a similarly mixed picture for owner management of their dogs' food intake. 'Owner intervention to control weight' mapped to 'control over eating', though many dog owners exert far more rigorous control than even strict parents. Giving human food to dogs is similar to instrumental or emotional feeding. Prompting/encouragement to eat is the final construct on the Parental Feeding Style questionnaire (Carnell \& Wardle 2007). During interviews, it was apparent that many dog owners added flavoursome items to their dogs' regular food, but they appeared to have very variable motivation (e.g. 'it uses leftovers', 'he won't eat biscuits without gravy', 'it bulks him out without many calories') and occur in dogs with different foodmotivation. This proved too complex to capture on the DORA questionnaire and would be unlikely to inform the causes of canine obesity or define appetite so was not included. 
581 In summary, the DORA questionnaire has proven to be a robust, easily applicable owner 582 reported questionnaire to assess dog food-motivation and owner management. Following the

583 validation, data was analysed to test the association between dog eating behaviour and owner 584 management.

585 Variability in Canine Food-Motivation and Owner Management

586 This is the first time food-motivation has been shown to vary considerably between individual

587 dogs and between dog breeds. Dogs which were more highly food-motivated were shown to be 588 more commonly overweight. Indeed, food-motivation had similar magnitude of effect to 589 exercise and owners feeding their dogs human food in the minimum model for factor association 590 with body condition score. To date, the literature, veterinary surgeons and surrounding debate 591 has emphasised owner failure to control diet and exercise as the major reasons for dogs 592 becoming obese (Bland et al. 2010; Degeling et al. 2011). However, this finding would suggest 593 dogs' individual drive to eat is as important as those factors.

594 The significant difference in food-motivation between breed groups is notable and, viewed 595 alongside previously reported breed predispositions to obesity, suggests a genetic influence on 596 food-motivation and obesity (Colliard et al. 2006; Edney \& Smith 1986; O'Neill et al. 2014). An 597 alternative explanation would be that owners of particular breeds of dog somehow manage their 598 dogs in such a way as to encourage food-seeking behaviour. However, the authors find it 599 implausible that owners of particular breed groups would a) have a tendency to feed and exercise 600 their dogs in a similar way, and b) that the differences between owners of different breeds would 601 be sufficiently consistent to explain the variability in appetite seen here.

602 Furthermore, the finding from this study that owners of more highly food-motivated dogs exert 603 greater control over their dog's food intake directly contradicts the commonly held view that 604 dogs only display food-seeking or begging behaviour because they have become habituated to 605 receiving food from indulgent owners. Rather, it suggests owners generally make efforts to 606 prevent the development of obesity as has been observed previously in parent/child relationships 607 (Carnell et al. 2011; Fildes et al. 2015).

608 In contrast, there was no association between high food-motivation and exercise, the other way 609 in which owners might limit their food-motivated dog's tendency towards gaining weight. This 610 likely reflects that the amount of exercise a dog receives is the net outcome of many conflicting 611 factors: highly food motivated dogs are more likely to be overweight, which mean they would 612 benefit from more exercise but also means they are likely to play less and exercise less

613 vigorously (German et al. 2012), even if time-constrained owners tried to increase their exercise .

\section{Limitations}

615 This is an owner-report measure and could be subject to bias. The best available comparators for

616 validation were the answers to questions during an in depth semi-structured interviews with

617 respondents. Generally, there was concordance between questionnaire responses and interview 
618 results. In the few cases where there was discordance, those items were eliminated. Ultimately,

619 the best way to validate the items relating to dog food-related behaviour would be comparison to

620 food intake trials in large numbers of pet dogs, but this is not feasible at present though that

621 approach has been used to validate the Child Eating Behaviour Questionnaire and will be

622 considered in future (Carnell and Wardle 2007). Similarly, owner management and exercise

623 items might best be compared to longitudinal monitoring using food diaries, video monitoring or

624 accelerometry (Chan and others 2005; Slater and others 1992).

625 The measure of obesity used was an owner-assessed body condition score. Dogs of different

626 breeds are very heterogeneous so weight is a poor indicator of obesity in the species. In contrast

627 condition scoring according to body morphometry following visual inspection and manual

628 palpation is well validated (Laflamme 1997). However, it is well recognised that owners tend to

629 assign inaccurate body condition scores to their dogs, usually assigning a score closer to the

630 'ideal' (Colliard et al. 2006; Courcier et al. 2011; White et al. 2011).

631 Consistent with this, $23 \%$ of owners in this study assigned their dogs body condition score 4 or

$6325 / 5$ (overweight/obese) despite the fact that estimates suggest obesity prevalence is at least $25 \%$

633 in the general dog population and many estimates suggest as high as $40 \%$ (German 2006;

634 McGreevy et al. 2005; O'Neill et al. 2014; Zoran 2010). Thus our data may not be robust enough

635 to compare the actual body condition scores to other studies, but the number of respondents and

636 normal distribution of body condition scores across the sample means it is reasonable to use the

637 scores to interrogate the data in the limited way demonstrated here. Furthermore, it is notable

638 that clear associations between different factors (dog food-motivation, restriction of human food

639 and exercise) and body condition score were identified, despite the fact that owner's tendency to

640 underestimate the body condition score of overweight dogs would have been predicted to reduce

641 the power of the study to detect such associations. Future work using more reliable, vet/nurse

642 assigned body condition scores would be of value.

\section{Future Applications}

644 The authors envisage that this questionnaire might be of value to others both in clinical practice

645 and research. Clinically, enumeration of food-motivation might help motivate owners to work

646 hard to restrict food and reduce some of the 'blame' often assigned to owners of obese dogs; this

647 would be an interesting future study to perform. Clinical researchers might use the questionnaire

648 to discover if management practices altered food-motivation, though application to a longitudinal

649 study would require further validation as this work did not examine if a dog's score would

650 change over months or years. Biomedical researchers using dogs to model obesity in other

651 species might find value in being able to quantify food-motivation as part of studies to test the

652 effect of genes, drugs or other variables on food intake and obesity.

\section{CONCLUSIONS}

654 We have developed and validated a robust, practical, user-friendly, owner-reported measure of

655 dog eating behaviour and of management and health factors with potential to affect the 
656 development of obesity in dogs. It will be a useful tool for research into obesity and related 657 behaviour, and in veterinary clinical practice. We have demonstrated that there is marked 658 variability in canine food-motivation both between individuals and breeds. Highly food659 motivated dogs are more likely to be obese, with food-motivation having as great an association 660 with obesity as owners giving titbits and exercise on body condition score. Finally, owners of 661 highly food-motivated dogs tend to exert greater control over their dogs' food intake. 


\section{REFERENCES}

663 Asher L, Buckland EL, Phylactopoulos Cl, Whiting MC, Abeyesinghe SM, and Wathes CM. 2011.

664 Estimation of the number and demographics of companion dogs in the UK. BMC Vet Res 7:74.

665 Belshaw Z, Asher L, Harvey N, and Dean RS. 2015. Quality of life assessment in domestic dogs:

666 An evidence-based rapid review. Veterinary Journal.

667 Bland IM, Guthrie-Jones A, Taylor RD, and Hill J. 2009. Dog obesity: owner attitudes and 668 behaviour. Prev Vet Med 92:333-340.

669 Bland IM, Guthrie-Jones A, Taylor RD, and Hill J. 2010. Dog obesity: veterinary practices' and owners' opinions on cause and management. Prev Vet Med 94:310-315.

671 Carnell S, Cooke L, Cheng R, Robbins A, and Wardle J. 2011. Parental feeding behaviours and 672 motivations. A qualitative study in mothers of UK pre-schoolers. Appetite 57:665-673.

673 Carnell S, and Wardle J. 2007. Measuring behavioural susceptibility to obesity: validation of the 674 child eating behaviour questionnaire. Appetite 48:104-113.

675 Carnell S, and Wardle J. 2009. Appetitive traits in children. New evidence for associations with weight and a common, obesity-associated genetic variant. Appetite 53:260-263.

677 Colliard L, Ancel J, Benet JJ, Paragon BM, and Blanchard G. 2006. Risk factors for obesity in dogs 678 in France. J Nutr 136:1951S-1954S.

679 Courcier EA, Mellor DJ, Thomson RM, and Yam PS. 2011. A cross sectional study of the 680 prevalence and risk factors for owner misperception of canine body shape in first opinion 681 practice in Glasgow. Prev Vet Med 102:66-74.

682 Courcier EA, Thomson RM, Mellor DJ, and Yam PS. 2010. An epidemiological study of 683 environmental factors associated with canine obesity. J Small Anim Pract 51:362-367.

684 Degeling C, Rock M, and Toews L. 2011. Portrayals of canine obesity in English-language 685 newspapers and in leading veterinary journals, 2000-2009: implications for animal welfare 686 organizations and veterinarians as public educators. J Appl Anim Welf Sci 14:286-303.

687 Edney AT, and Smith PM. 1986. Study of obesity in dogs visiting veterinary practices in the 688 United Kingdom. Vet Rec 118:391-396.

689 Farooqi IS. 2011. Genetic, molecular and physiological insights into human obesity. Eur J Clin 690 Invest 41:451-455. 
691 Fildes A, van Jaarsveld CH, Llewellyn C, Wardle J, and Fisher A. 2015. Parental control over

692 feeding in infancy. Influence of infant weight, appetite and feeding method. Appetite 91:101-

693106.

694 French SA, Epstein LH, Jeffery RW, Blundell JE, and Wardle J. 2012. Eating behavior dimensions.

695 Associations with energy intake and body weight. A review. Appetite 59:541-549.

696 German AJ. 2006. The growing problem of obesity in dogs and cats. J Nutr 136:1940S-1946S.

697 German AJ, Holden SL, Wiseman-Orr ML, Reid J, Nolan AM, Biourge V, Morris PJ, and Scott EM.

698 2012. Quality of life is reduced in obese dogs but improves after successful weight loss. Vet J

699 192:428-434.

700 Gibbons C, Finlayson G, Dalton M, Caudwell P, and Blundell JE. 2014. Metabolic Phenotyping

701 Guidelines: studying eating behaviour in humans. J Endocrinol 222:G1-12.

702 Gibbs GR. 2007. Thematic coding and categorizing. In: Gibbs GR, ed. Analyzing Qualitative Data.

703 London: Sage Publications Ltd, 38-56.

704 Hand MS, Thatcher CD, Remillard RL, Roudebush P, and Novotny BJ. 2010. Small Animal Clinical 705 Nutrition. Topeka, USA: Mark Morris Institute.

706 Hewson-Hughes AK, Hewson-Hughes VL, Colyer A, Miller AT, McGrane SJ, Hall SR, Butterwick 707 RF, Simpson SJ, and Raubenheimer D. 2013. Geometric analysis of macronutrient selection in 708 breeds of the domestic dog, Canis lupus familiaris. Behav Ecol 24:293-304.

709 Kienzle E, Bergler R, and Mandernach A. 1998. A comparison of the feeding behavior and the 710 human-animal relationship in owners of normal and obese dogs. J Nutr 128:2779S-2782S.

711 Laflamme DP. 1997. Development and validation of a body condition score system for dogs.

712 Canine Pract 22:10-15.

713 Lindell E. 2009. Management problems in dogs. In: Horwitz D, and Mills D, eds. BSAVA Manual 714 of Canine and Feline Behavioural Medicine. 2 ed. Birmingham: BSAVA, 83-97.

715 Llewellyn $\mathrm{CH}$, van Jaarsveld $\mathrm{CH}$, Johnson L, Carnell S, and Wardle J. 2011. Development and

716 factor structure of the Baby Eating Behaviour Questionnaire in the Gemini birth cohort.

717 Appetite 57:388-396.

718 McGreevy PD, Thomson PC, Pride C, Fawcett A, Grassi T, and Jones B. 2005. Prevalence of 719 obesity in dogs examined by Australian veterinary practices and the risk factors involved. Vet 720 Rec 156:695-702. 
721 Nijland ML, Stam F, and Seidell JC. 2010. Overweight in dogs, but not in cats, is related to

722 overweight in their owners. Public Health Nutr 13:102-106.

723 O'Neill D, Church DB, McGreevy PD, Thomson PC, and Brodbelt DC. 2014. Prevalence of 724 disorders recorded in dogs attending primary-care veterinary practices in England. PLoS One 725 9:e90501.

726 R Core Team. 2013. $R$ : A language and environment for statistical computing. Vienna, Austria: $R$ 727 Foundation for Statistical Computing.

728 Raffan E. 2013. The big problem: battling companion animal obesity. Veterinary Record 729 173:287-291.

730 Revelle W. 2015. psych: Procedures for Psychological, Psychometric, and Personality Research. 731 Available at http://CRAN.R-project.org/package=psych (accessed 01/02/2015 2015).

732 Robertson ID. 2003. The association of exercise, diet and other factors with owner-perceived 733 obesity in privately owned dogs from metropolitan Perth, WA. Prev Vet Med 58:75-83.

734 Rohlf VI, Toukhsati S, Coleman GJ, and Bennett PC. 2010. Dog obesity: can dog caregivers' 735 (owners') feeding and exercise intentions and behaviors be predicted from attitudes? J Appl 736 Anim Welf Sci 13:213-236.

737 Sallander M, Hagberg M, Hedhammar A, Rundgren M, and Lindberg JE. 2010. Energy-intake and 738 activity risk factors for owner-perceived obesity in a defined population of Swedish dogs. Prev 739 Vet Med 96:132-141.

740 van Strien T, Frijters JER, Bergers GPA, and Defares PB. 2006. The Dutch Eating Behavior 741 Questionnaire (DEBQ) for assessment of restrained, emotional, and external eating behavior. 742 International Journal of Eating Disorders 5:295-315.

743 Wardle J, Guthrie CA, Sanderson S, and Rapoport L. 2001. Development of the Children's Eating 744 Behaviour Questionnaire. J Child Psychol Psychiatry 42:963-970.

745 Warren BS, Wakshlag JJ, Maley M, Farrell TJ, Struble AM, Panasevich MR, and Wells MT. 2011. 746 Use of pedometers to measure the relationship of dog walking to body condition score in obese 747 and non-obese dogs. Br J Nutr 106 Suppl 1:S85-89.

748 White GA, Hobson-West P, Cobb K, Craigon J, Hammond R, and Millar KM. 2011. Canine 749 obesity: is there a difference between veterinarian and owner perception? J Small Anim Pract $750 \quad 52: 622-626$.

751 Wickham H. 2009. ggplot2: elegant graphics for data analysis. New York, USA: Springer. 
752 Yeo GS, and Heisler LK. 2012. Unraveling the brain regulation of appetite: lessons from genetics.

753 Nat Neurosci 15:1343-1349.

754 Zoran DL. 2010. Obesity in dogs and cats: a metabolic and endocrine disorder. Vet Clin North

755 Am Small Anim Pract 40:221-239.

756

757 
758

759

760

761

762

763

764

765

766

767

768

769

770

771

772

773

774

775

776

777

778

779

780

781

782

783

784

785

786

787

788

789

790

791

792

\section{TABLES}

Table 1: Factor loadings for all dog (food-motivation) factors in the questionnaire. a Items marked $(R)$ have been reversed for scoring purposes. ${ }^{b}$ All factor loadings of greater magnitude than 0.1 are shown and those $>0.4$ are shown in bold.

Table 2: Factor loadings for all management and health factors in the questionnaire. ${ }^{a}$ Items marked $(R)$ have been reversed for scoring purposes. ${ }^{b}$ All factor loadings of greater magnitude than 0.1 are shown and those $>0.4$ are shown in bold. ${ }^{c}$ These items loaded onto more than one factor, but were grouped where they loaded most strongly. ${ }^{d}$ Although factors Exercise 1 and Exercise 2 were identified separately under factor analysis, they were considered as a single factor for scoring. ${ }^{e}$ These questions did not load onto any factor, which is not surprising given that they are not directly weight, food or exercise related. However, they were retained in the questionnaire as a way to flag up the possibility that a dog has a chronic health problem which might in some way confound the weight or appetite phenotype. * Factors 1-3 were combined to generate the 'owner management score'.

Table 3: Test-retest reliability for sample 3 respondents who completed the questionnaire on two occasions, two weeks apart $(n=67)$. Shown are the correlation coefficient, $R$, and significance, $P$ between scores for each factor at the different time points. Cronbach's alpha, a measure of internal consistency, is shown for each factor.

Table 4: Questions retained despite high skew, low communality or high complexity. Numbers in normal font are within the pre-defined boundaries for inclusion. Numbers in bold are outside those boundaries and would have been discarded as routine but items were retained for a particular reason or reasons.

Table 5: Spearman correlation coefficients for scores for dog and owner management factors. (a) dog factors and (b) management factors. A Bonferroni corrected level of significance of $p<$ 0.001 was used. Significant correlations are shown in bold and non-significant correlations are shown in parentheses.

\section{FIGURES}

Figure 1: Flow diagram summarising validation and application steps for the DORA questionnaire.

Figure 2: Frequency histogram showing distribution of owner assigned body condition scores.

Figure 3: Frequency histogram showing distribution of dog food motivation scores. If Labrador retriever dogs were removed from the analysis, the distribution pattern remained almost identical.

91 Figure 4: Box and whisker plot showing difference in dog food-motivation scores between breed groups. 
793 Figure 5: Frequency histograms showing distribution of (a) owner management, (b) exercise, (c)

794 current disease and (d) signs of GI disease scores.

795 Figure 6: Scatter plot showing difference in dog food-motivation scores between dogs with

796 different owner-assigned body condition scores. Median and standard deviation superimposed

797 as lines. (ANOVA $p=0.0041)$

798 Figure 7: Owners of more food-motivated or overweight dogs made a statistically significantly

799 greater effort to control their dogs' food intake. (a) Scatter plot showing correlation between

800 dog food-motivation and owner management scores. Spearman correlation $r s=0.30, p=$

801 0.00001. (b) Box and whisker plot showing difference in owner management scores between

802 dogs with different body condition scores. Boxes extend to 25 th and 75 th percentiles, central

803 line shows median, whiskers the minimum and maximum values. Pearson correlation coefficient

$804 r=0.19, p=0.01$.

805 


\section{Table $\mathbf{1}$ (on next page)}

Factor loadings for all dog (food-motivation) factors in the questionnaire.

${ }^{\mathrm{a}}$ Items marked (R) have been reversed for scoring purposes. ${ }^{\mathrm{b}}$ All factor loadings of greater magnitude than 0.1 are shown and those $>0.4$ are shown in bold. 


\begin{tabular}{|c|c|c|c|}
\hline Item $^{\mathrm{a}}$ & Factor analysis & & \\
\hline & $\begin{array}{c}\text { Food } \\
\text { responsiveness } \\
\text { and satiety }\end{array}$ & Choosiness & $\begin{array}{l}\text { Interest in } \\
\text { food }\end{array}$ \\
\hline \multicolumn{4}{|l|}{ Dog factor 1: Food responsiveness and satiety } \\
\hline My dog gets excited when there is food around & 0.63 & & 0.29 \\
\hline My dog will turn down food if $s /$ he is not hungry $(R)$ & -0.70 & 0.21 & \\
\hline My dog finishes a meal straight away & 0.96 & & -0.17 \\
\hline After a meal my dog is still interested in eating & 0.52 & -0.14 & 0.38 \\
\hline My dog takes his her time to eat a meal ( $R$ ) & -0.84 & & \\
\hline My dog seems to be hungry all the time & 0.41 & & 0.33 \\
\hline My dog is very greedy & 0.54 & -0.10 & 0.37 \\
\hline \multicolumn{4}{|l|}{ Dog factor 2: Lack of fussiness } \\
\hline $\begin{array}{l}\text { My dog inspects unfamiliar foods before deciding whether to eat } \\
\text { them }(R)\end{array}$ & & 0.79 & 0.12 \\
\hline My dog is choosy about which titbits he eats ( $R$ ) & & 0.71 & \\
\hline My dog would eat anything & & -0.79 & \\
\hline \multicolumn{4}{|l|}{ Dog factor 3: Interest in food } \\
\hline $\begin{array}{l}\text { My dog hangs around for titbits even if there is not much chance } \\
\text { of getting them }\end{array}$ & & & 0.79 \\
\hline My dog hangs around when I am preparing or eating human food & -0.12 & & 0.75 \\
\hline My dog eats titbits straight away & 0.19 & -0.27 & 0.32 \\
\hline
\end{tabular}




\section{Table 2 (on next page)}

Factor loadings for all management and health factors in the questionnaire.

${ }^{\mathrm{a}}$ Items marked (R) have been reversed for scoring purposes. ${ }^{\mathrm{b}} \mathrm{All}$ factor loadings of greater magnitude than 0.1 are shown and those $>0.4$ are shown in bold. ' These items loaded onto more than one factor, but were grouped where they loaded most strongly. ${ }^{d}$ Although factors Exercise 1 and Exercise 2 were identified separately under factor analysis, they were considered as a single factor for scoring. ${ }^{e}$ These questions did not load onto any factor, which is not surprising given that they are not directly weight, food or exercise related. However, they were retained in the questionnaire as a way to flag up the possibility that a dog has a chronic health problem which might in some way confound the weight or appetite phenotype. * Factors 1-3 were combined to generate the 'owner management score'. 


\begin{tabular}{|c|c|c|c|c|c|c|}
\hline \multirow{2}{*}{$\begin{array}{c}1 \\
\text { Item }^{\mathrm{a}}\end{array}$} & \multicolumn{6}{|c|}{ Factor Loadings $^{b}$} \\
\hline & $\begin{array}{l}\text { Owner } \\
\text { perception }\end{array}$ & $\begin{array}{c}\text { Owner } \\
\text { interventions }\end{array}$ & $\begin{array}{l}\text { Human } \\
\text { food }\end{array}$ & $\begin{array}{l}\text { Exercise } \\
1^{\mathrm{d}}\end{array}$ & $\begin{array}{l}\text { Exercise } \\
\quad 2^{d}\end{array}$ & $\begin{array}{l}\text { Signs GI } \\
\text { disease }\end{array}$ \\
\hline \multicolumn{7}{|l|}{$1^{*}:$ Owner perception } \\
\hline I am happy with my dog s weight $(R)$ & 0.81 & & & & & \\
\hline I think my dog could do with losing some weight & -0.92 & & & & & \\
\hline My dog is very fit (R) & 0.52 & & & $0.43^{c}$ & & \\
\hline \multicolumn{7}{|l|}{$2 *:$ Owner intervention to control weight } \\
\hline $\begin{array}{l}\text { I am careful to regulate the exercise my dog gets } \\
\text { in order to keep him her slim }\end{array}$ & -0.13 & $0.47^{c}$ & & $0.4^{c}$ & & \\
\hline $\begin{array}{l}\text { I alter the food my dog gets in order to control his } \\
\text { her weight }\end{array}$ & -0.28 & 0.6 & & & & \\
\hline I am careful about my dog's weight & 0.17 & 0.75 & & & & \\
\hline I weigh or measure how much food I give my dog & & 0.49 & & & & \\
\hline \multicolumn{7}{|l|}{$3^{*}:$ Restriction of human food } \\
\hline My dog gets no food at human mealtimes & & & -0.69 & & & \\
\hline $\begin{array}{l}\text { My dog gets human leftovers in his her food bowl } \\
\text { (R) }\end{array}$ & & -0.1 & 0.59 & & & \\
\hline $\begin{array}{l}\text { My dog gets bits of human food when we are } \\
\text { eating (R) }\end{array}$ & & & 0.85 & & 0.13 & \\
\hline My dog often gets human food (R) & & & 0.78 & & -0.13 & \\
\hline \multicolumn{7}{|l|}{ 4: Exercise taken } \\
\hline My dog runs around a lot & 0.16 & & & 0.72 & & \\
\hline $\begin{array}{l}\text { My dog's walks involve a lot of energetic play or } \\
\text { chasing }\end{array}$ & & & & 0.72 & -0.15 & \\
\hline My dog gets a lot of exercise & & & & 0.71 & & \\
\hline My dog s walks are mostly on the lead (R) & & & & & 0.88 & \\
\hline My dog spends most of his her walks off the lead & & & & & -0.9 & \\
\hline \multicolumn{7}{|l|}{ 5: Signs GI disease } \\
\hline My dog gets an upset tummy on some foods & 0.11 & & & & & 0.78 \\
\hline My dog has a sensitive stomach & & & & & & 0.88 \\
\hline My dog often gets tummy upsets & & -0.1 & & 0.11 & & 0.73 \\
\hline \multicolumn{7}{|l|}{ 6: Current disease } \\
\hline My dog regularly sees the vet for health problems ${ }^{\mathrm{e}}$ & -0.12 & 0.14 & & & & 0.11 \\
\hline $\begin{array}{l}\text { I restrict my dog's exercise because of veterinary } \\
\text { advice }\end{array}$ & -0.13 & & 0.11 & -0.12 & 0.24 & \\
\hline
\end{tabular}




\section{Table 3 (on next page)}

Test-retest reliability and internal consistency.

Data based on sample 3 respondents who completed the questionnaire on two occasions, two weeks apart ( $n=67)$. Shown are the correlation coefficient, $R$, and significance, $P$ between scores for each factor at the different time points. Cronbach's alpha, a measure of internal consistency, is shown for each factor. 


\begin{tabular}{lccc}
\hline Test-retest reliability & $\begin{array}{c}\text { Internal } \\
\text { Consistency }\end{array}$ \\
\hline $\begin{array}{l}\text { Food responsiveness } \\
\text { and satiety }\end{array}$ & $\mathrm{R}$ & P value & $\begin{array}{c}\text { Cronbach's } \\
\text { alpha }\end{array}$ \\
\hline Choosiness & 0.95 & $>1 \times 10^{-9}$ & 0.91 \\
\hline Interest in food & 0.89 & $>1 \times 10^{-9}$ & 0.81 \\
\hline Management factors & 0.81 & $>1 \times 10^{-9}$ & 0.73 \\
\hline Owner perception & 0.57 & $4 \times 10^{-7}$ & 0.86 \\
\hline Owner intervention & 0.80 & $>1 \times 10^{-9}$ & 0.65 \\
\hline Human food & 0.71 & $>1 \times 10^{-9}$ & 0.80 \\
\hline Exercise 1 & 0.86 & $>1 \times 10^{-9}$ & 0.77 \\
\hline Exercise 2 & 0.81 & $>1 \times 10^{-9}$ & 0.89 \\
\hline Signs GI disease & 0.78 & $>1 \times 10^{-9}$ & 0.83 \\
& & &
\end{tabular}




\section{Table 4 (on next page)}

Questions retained despite high skew, low communality or high complexity.

Numbers in normal font are within the pre-defined boundaries for inclusion. Numbers in bold are outside those boundaries and would have been discarded as routine but were retained for a particular reason or reasons. 
Parameter (cut-off for exclusion)

\begin{tabular}{|c|c|c|c|c|}
\hline Item Retained & $\begin{array}{c}\text { Skew } \\
(<-1.25 \text { or }>1.25)\end{array}$ & $\begin{array}{c}\text { Communality } \\
(<0.35)\end{array}$ & $\begin{array}{c}\text { Complexity } \\
(>3)\end{array}$ & Reason for Retention \\
\hline $\begin{array}{l}\text { My dog eats titbits } \\
\text { straight away }\end{array}$ & -1.58 & 0.38 & 2.70 & $\begin{array}{l}\text { Skew suggests most owners } \\
\text { report this item was not true } \\
\text { about their dog. During semi- } \\
\text { structured interviews this was } \\
\text { identified as a strong } \\
\text { discriminator between dogs with } \\
\text { high food-motivation and those } \\
\text { which were notably 'picky' or } \\
\text { 'fussy' with food. }\end{array}$ \\
\hline
\end{tabular}

\begin{tabular}{|c|c|c|c|c|}
\hline $\begin{array}{l}\text { My dog finishes a meal } \\
\text { straight away }\end{array}$ & -1.66 & 0.69 & 3.11 & As above. \\
\hline $\begin{array}{l}\text { I think my dog could do } \\
\text { with losing some weight }\end{array}$ & 1.33 & 1.02 & 0.89 & $\begin{array}{l}\text { Echoed phrase used by } \\
\text { interviewees who acknowledged } \\
\text { dog was overweight. Skew } \\
\text { expected given that only a } \\
\text { proportion of dogs are genuinely } \\
\text { overweight. }\end{array}$ \\
\hline $\begin{array}{l}\text { My dog often gets } \\
\text { human food }\end{array}$ & 1.22 & 0.29 & 3.3 & $\begin{array}{l}\text { Next best performer in this factor } \\
\text { and considered important because } \\
\text { did not specify when the dog was } \\
\text { given human food (c.f. other } \\
\text { items in factor relating to } \\
\text { mealtimes, leftovers, etc.) }\end{array}$ \\
\hline My dog is very fit & -0.79 & 0.50 & 3.1 & $\begin{array}{l}\text { Echoed phrase commonly } \\
\text { volunteered by interviewees with } \\
\text { lean dogs and next best performer } \\
\text { in the 'Owner perception' factor. }\end{array}$ \\
\hline $\begin{array}{l}\text { I restrict my dog's } \\
\text { exercise because of } \\
\text { veterinary advice }\end{array}$ & 3.65 & 0.46 & 1.32 & $\begin{array}{l}\text { A warning sign of ill health or } \\
\text { orthopaedic disease of potential } \\
\text { value to researchers. }\end{array}$ \\
\hline $\begin{array}{l}\text { My dog has a sensitive } \\
\text { stomach }\end{array}$ & 1.27 & 0.21 & 3.5 & $\begin{array}{l}\text { A warning sign of possible GI } \\
\text { disease of potential value to } \\
\text { researchers. }\end{array}$ \\
\hline
\end{tabular}


Table 5 (on next page)

Spearman correlation coefficients for scores for dog and owner management factors.

(a) dog factors and (b) management factors. A Bonferroni corrected level of significance of $p$ $<0.001$ was used. Significant correlations are shown in bold and non-significant correlations are shown in parentheses. 


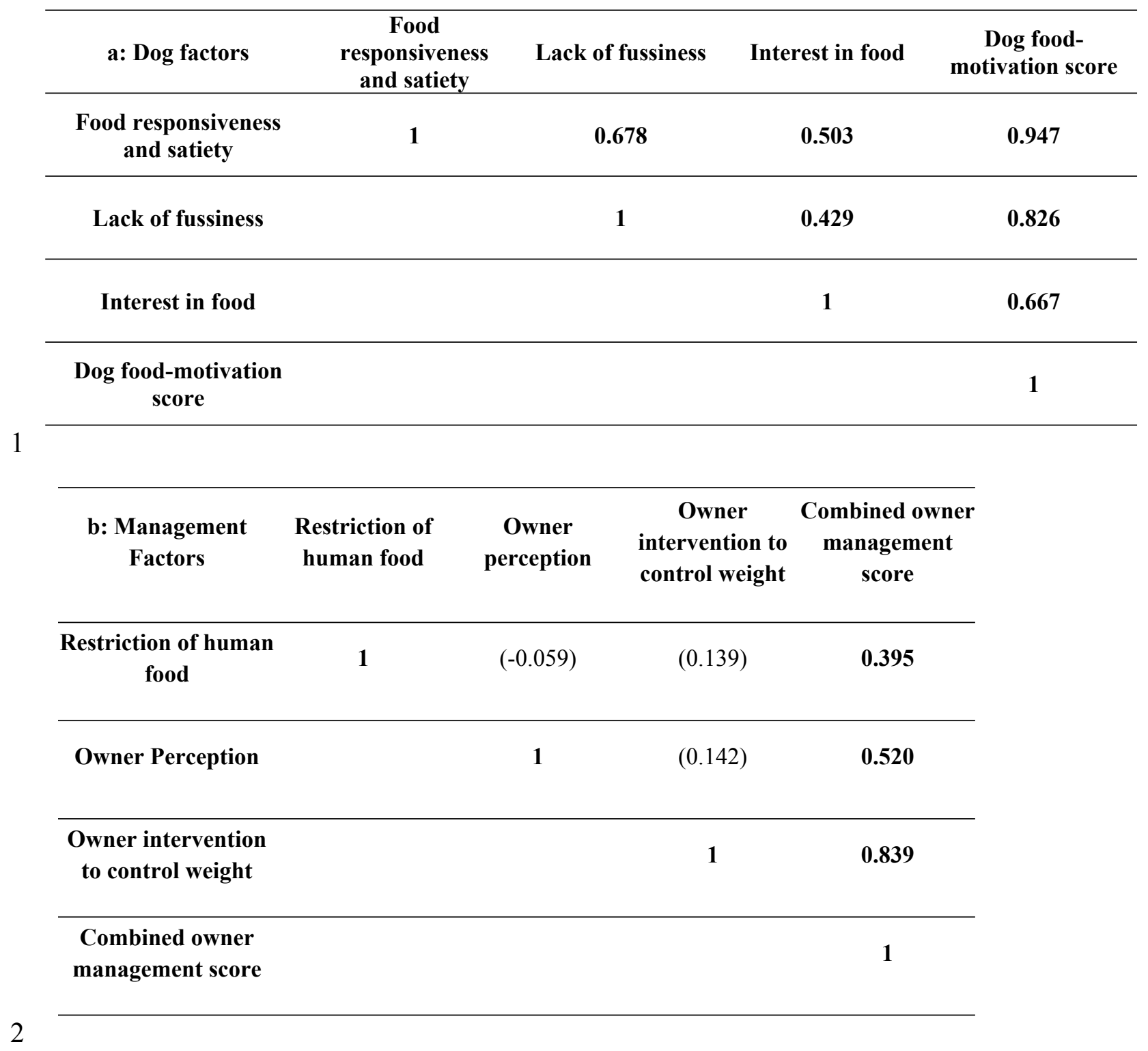


Flow diagram summarising validation and application steps for the DORA questionnaire.

Aim

Defining variability in food related behaviour

Generation of items

for questionnaire

Pilot survey: Identifying and addressing initial problems

Factor structure \& questionnaire refinement

\section{Method}

Review of dog and human literature

Semi-structured interviews with 50 dog owners

Systematic analysis of interview data

Generate 77 item pilot questionnaire

Test questionnaire on expert panel and 22 dog owners Modify response format, question wording, discard 2 items

Analyse results from 224 owners

Exploratory factor analysis \& discard skewed or complex items Others rejected to produce final 34 item questionnaire
Validation achieved

$\longrightarrow$ Face validity

Internal consistency

Test-retest reliability

Construct validity

Test for hypothesised relationships between factors

Criterion validity

Test whether food-motivation and managme
different between previously defined groups

Analyse findings from this

Define variability in food-motivation and managment/health factors application of questionnaire

Test for association with obesity 
2

Frequency histogram showing distribution of owner assigned body condition scores.

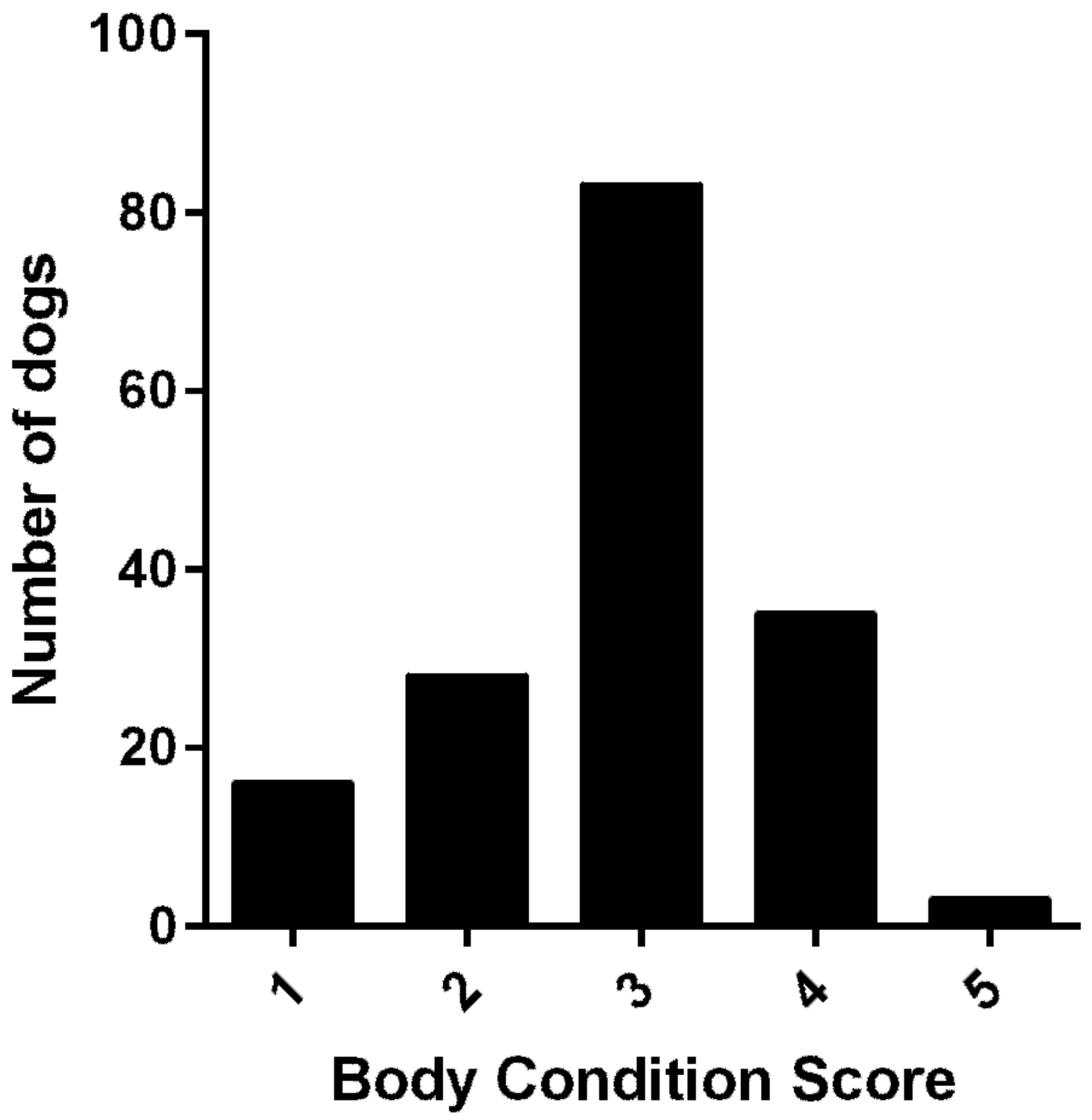




\section{3}

Frequency histogram showing distribution of dog food motivation scores.

If Labrador retriever dogs were removed from the analysis, the distribution pattern remained almost identical.

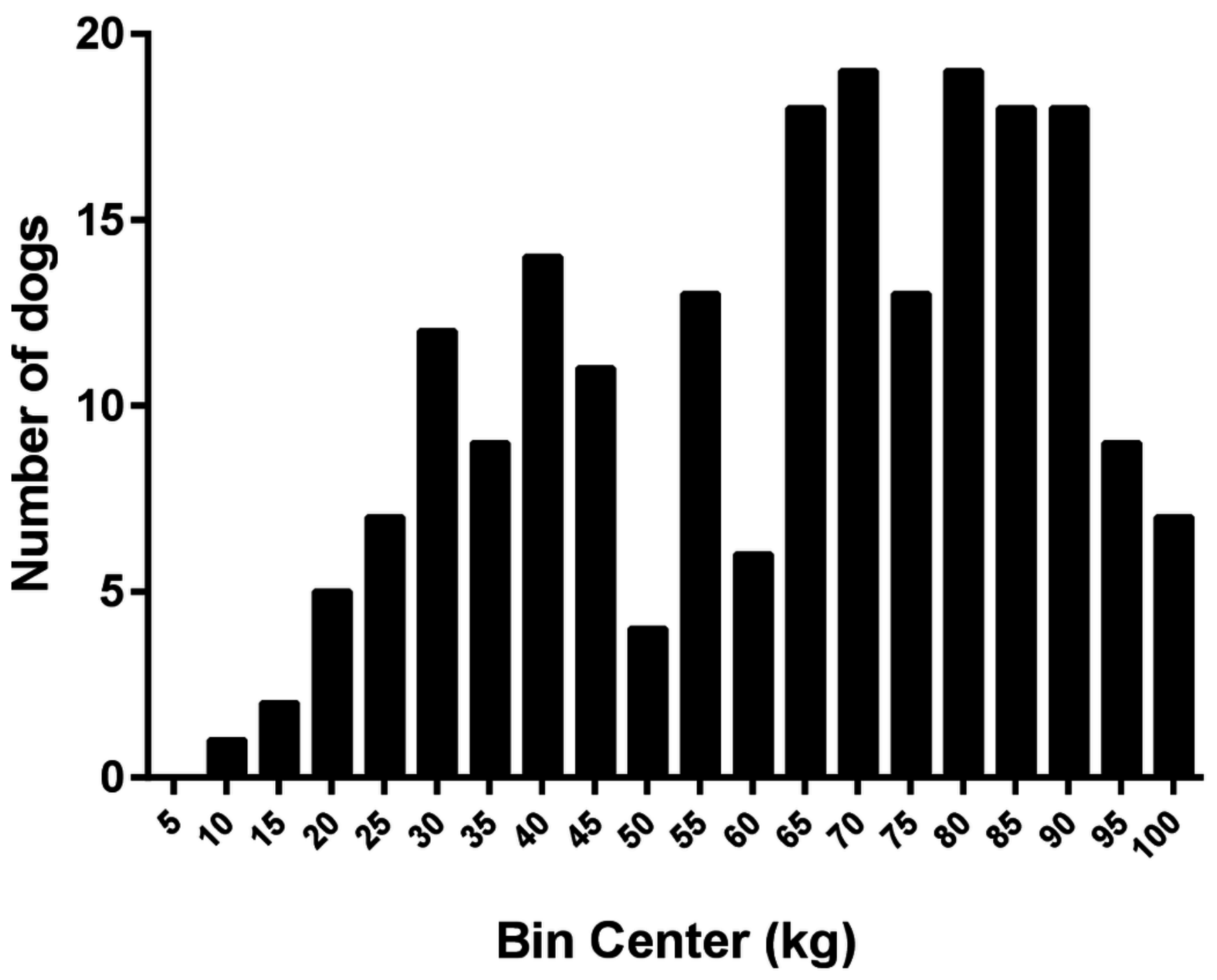


4

Box and whisker plot showing difference in dog food-motivation scores between breed groups.

Boxes extend to 25th and 75th percentiles, central line shows median, whiskers the minimum and maximum values. 


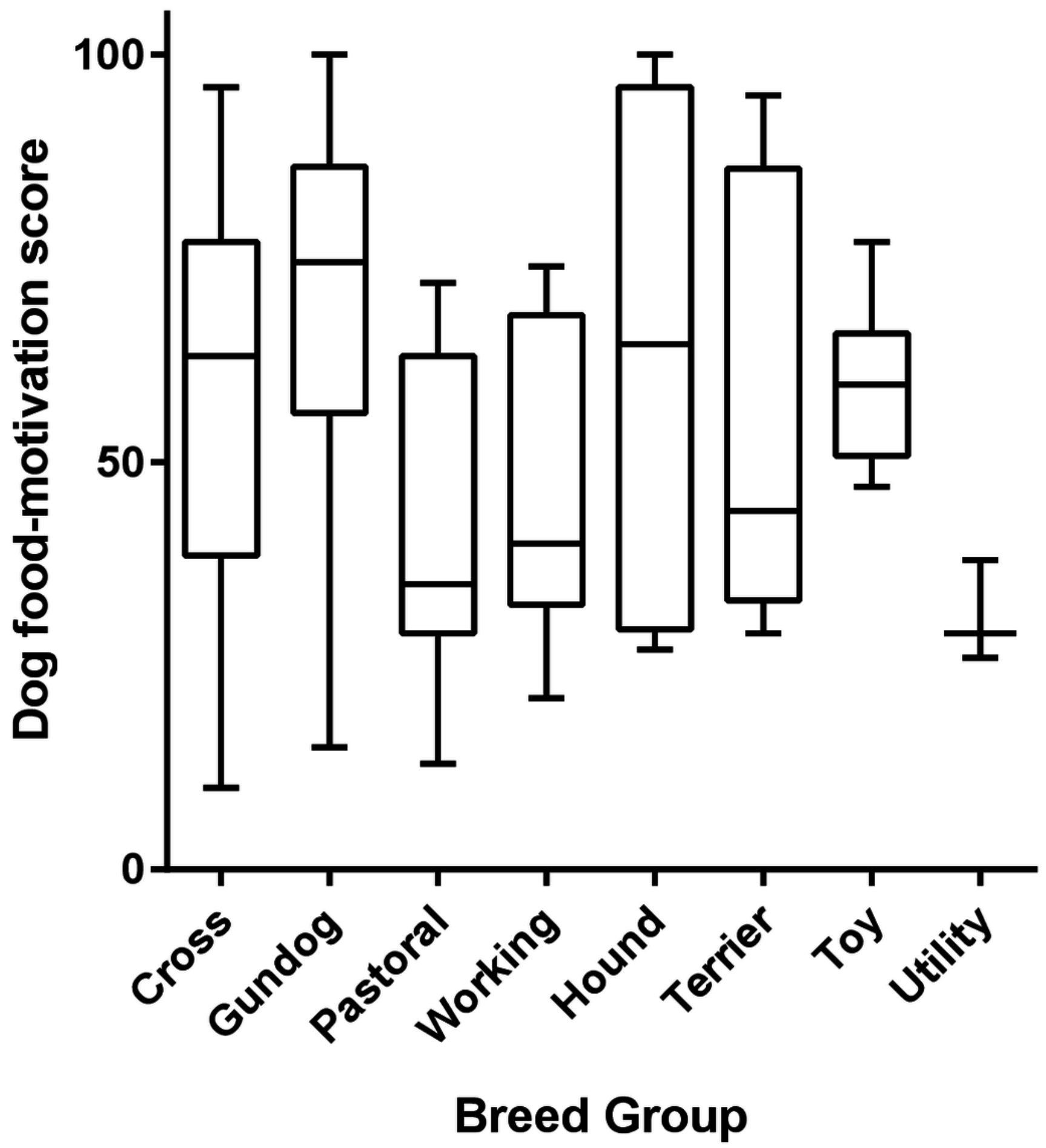




\section{5}

Frequency histograms showing distribution of factor scores.

(a) owner management, (b) exercise, (c) current disease and (d) signs of Gl disease scores.

(a)

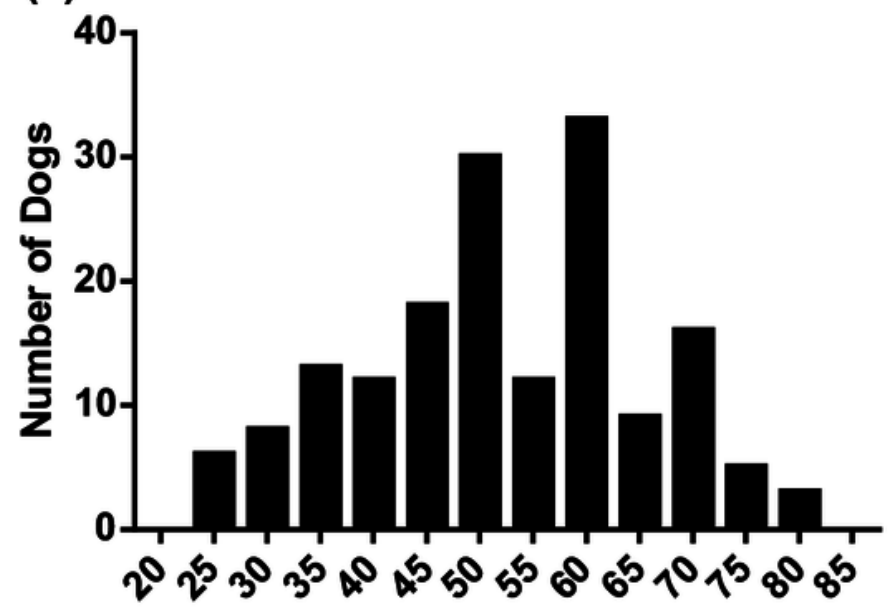

Bin Center Owner Managment Scores (\%)

(c)

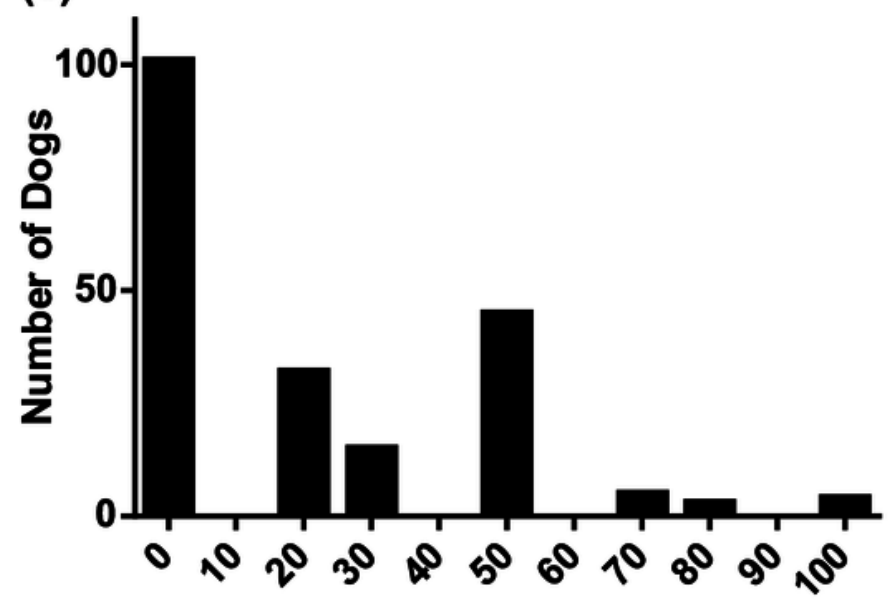

Bin Center Current Disease Score (\%) (b)

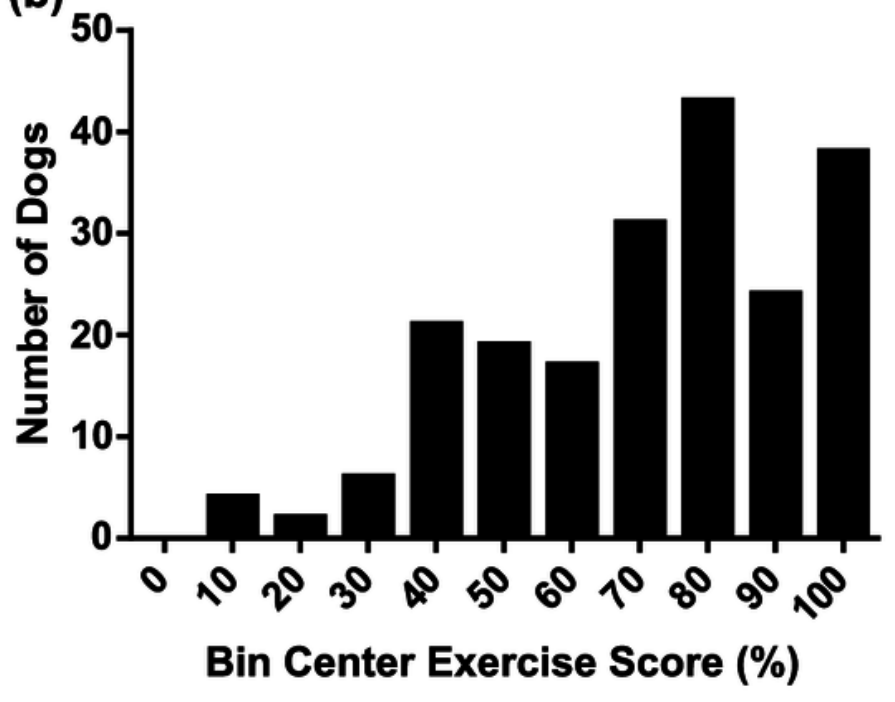

(d)

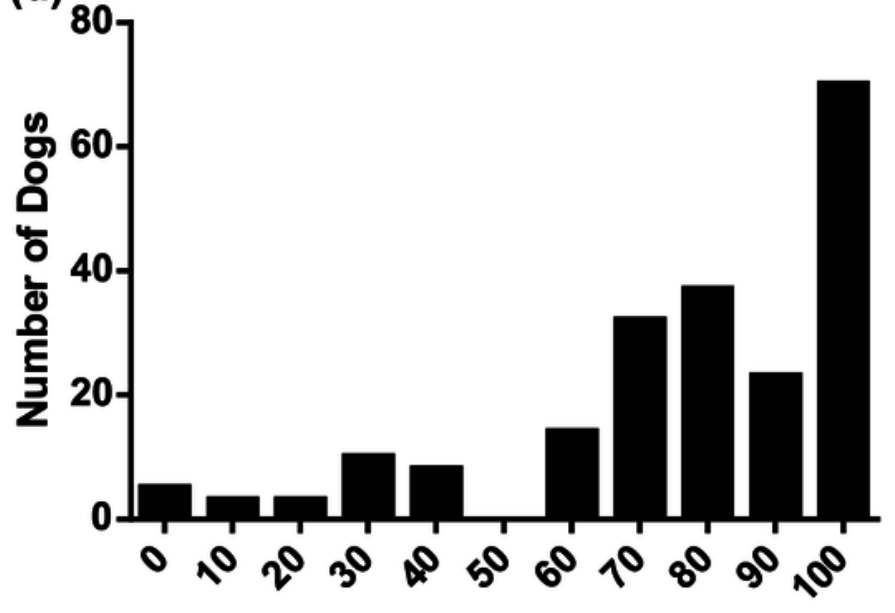

Bin Center Signs GI Disease Score (\%) 
6

Scatter plot showing difference in dog food-motivation scores between dogs with different owner-assigned body condition scores.

Median and standard deviation superimposed as lines. (ANOVA $p=0.0041$ )

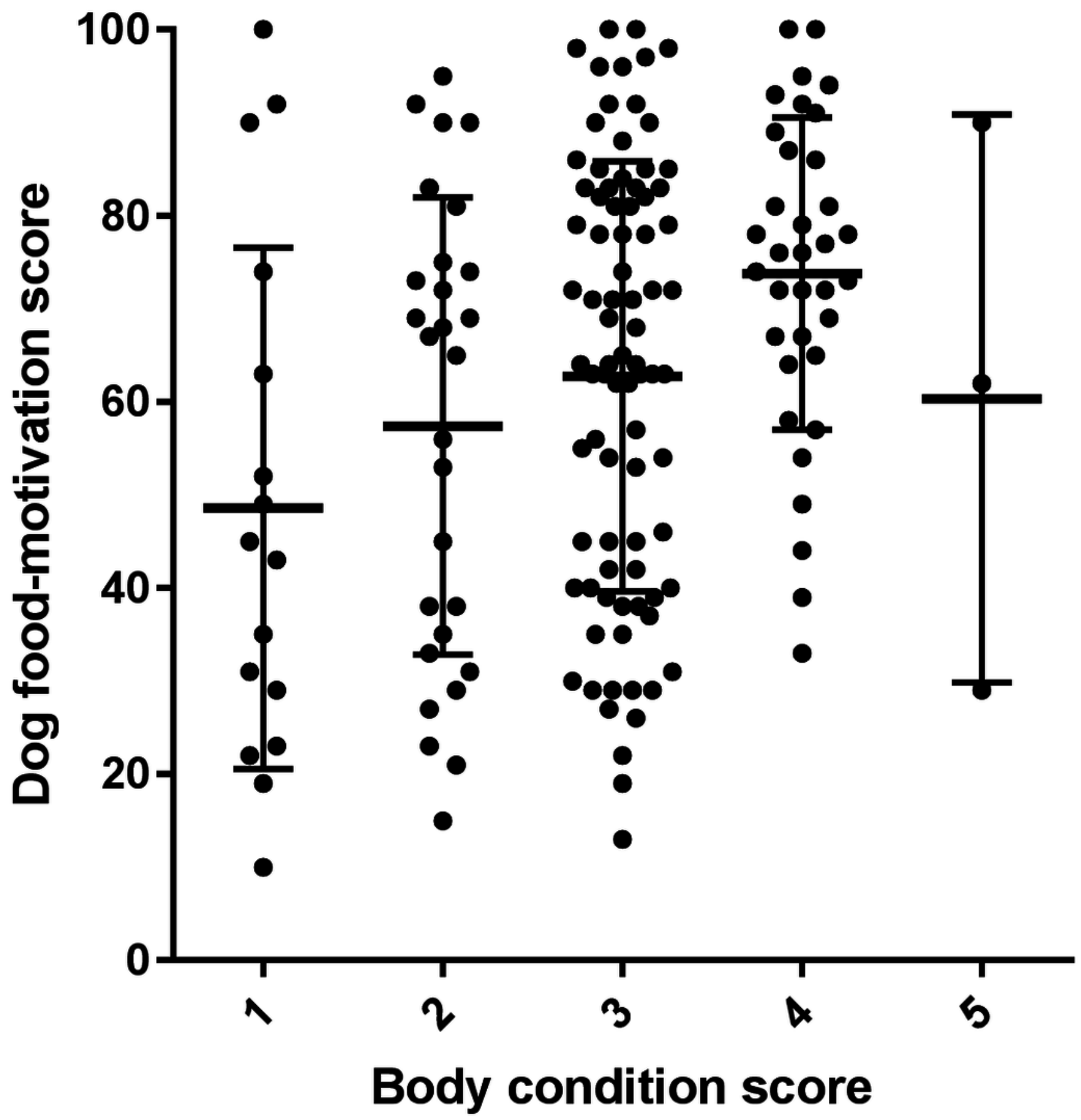


Figure $7_{\text {(on next page) }}$

Owners of more food-motivated or overweight dogs made a statistically significantly greater effort to control their dogs' food intake.

(a) Scatter plot showing correlation between dog food-motivation and owner management scores. Spearman correlation $r s=0.30, p=0.00001$. (b) Box and whisker plot showing difference in owner management scores between dogs with different body condition scores. Boxes extend to 25th and 75th percentiles, central line shows median, whiskers the minimum and maximum values. Pearson correlation coefficient $r=0.19, p=0.01$. 
(b)

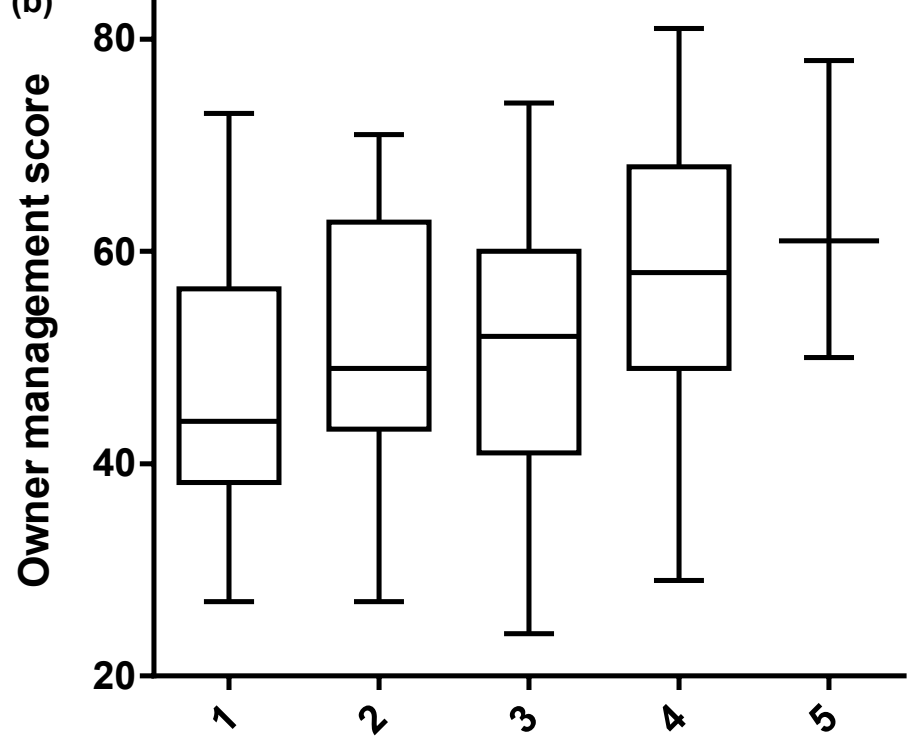

Body condition score

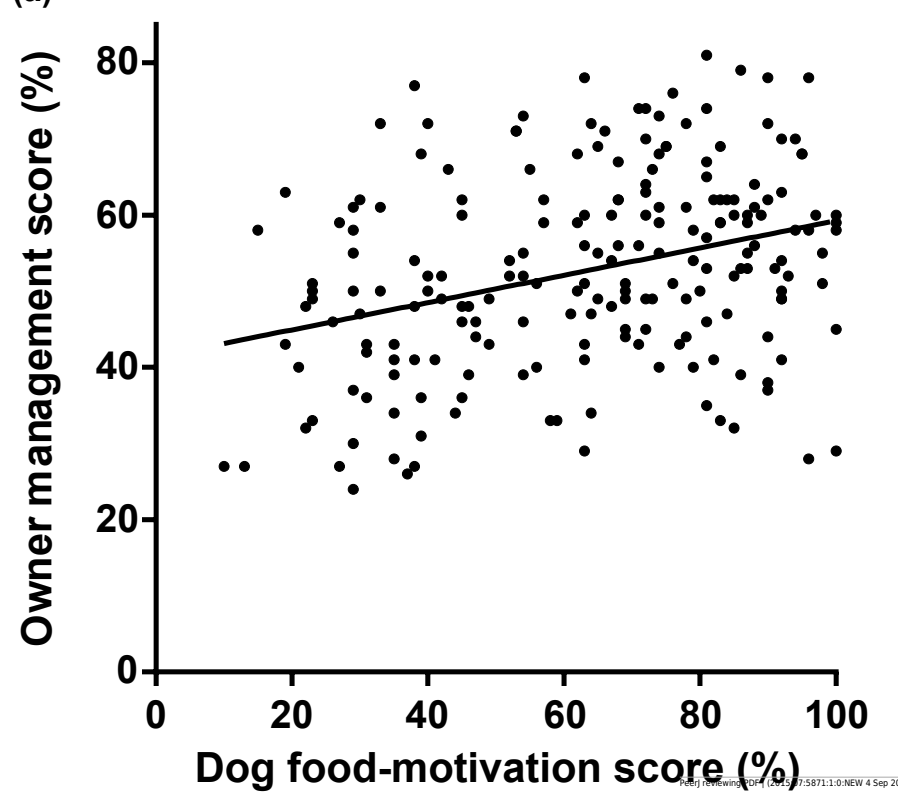

